\title{
Blepharophimosis plus ovarian failure: a likely candidate for a contiguous gene syndrome
}

\author{
A SMITH*, I S FRASER $\dagger$, R P SHEARMAN $\dagger$, AND P RUSSELL \\ From *the Cytogenetics Unit, Oliver Latham Laboratory, NSW Department of Health; †Department of \\ Obstetrics and Gynaecology, Sydney University; and $¥$ Department of Anatomical Pathology, Royal Prince \\ Alfred Hospital, Sydney, Australia.
}

SUMMARY We describe four females from three families with blepharophimosis, epicanthus inversus, and ptosis who were found to have premature ovarian failure. In two families the inheritance was autosomal dominant and in one it was a new mutation. Two females had, in addition, dysmorphic facial features which have been described in other cases. We suggest that the aetiology of the blepharophimosis ovarian failure syndrome is a contiguous gene syndrome.

The concept of a collection of phenotypic features resulting from a contiguous gene syndrome (CGS) is relatively new. ${ }^{1}$ A CGS results from microdeletion of part or all of a segment of genetic material containing several genes. A CGS should be considered whenever a patient has features of two (or more) known genetic but unrelated disorders. Clues to the localisation within the genome have mostly come from previous knowledge of at least one of these disorders, such as in the cases associated with Duchenne muscular dystrophy on $\mathrm{Xp} 21^{2}$ or because of structural chromosome change. ${ }^{34}$

Blepharophimosis is a rare congenital dysplasia of the eyelids with small palpebral fissures and, when associated with epicanthus inversus and ptosis, is known as the BPES syndrome. ${ }^{56}$ Some cases also have a variety of dysmorphic features ${ }^{7}$ and others have been associated with mental retardation. ${ }^{89}$ BPES is inherited in an autosomal dominant manner. An association with female infertility and amenorrhoea has been recognised in family studies ${ }^{10}$ and Jones and Collin ${ }^{11}$ confirmed a high incidence of gynaecological irregularities. Affected males are not infertile. Zlotogora et al $^{12}$ showed that blepharophimosis is heterogeneous and it seems likely that two types of the blepharophimosis syndrome exist. Type 1 is associated with female infertility and type 2 is not. Pathogenesis of BPES is not known but has been considered to result from a genetic defect acting at the third month of intrauterine life. ${ }^{7}$

We have recently seen four women with an association of blepharophimosis, secondary amenor-

Received for publication 22 August 1988.

Revised version accepted for publication 24 January 1989. rhoea, raised serum gonadotrophins, and infertility and have reported the ovarian biopsy and gynaecological findings in detail. ${ }^{13}$ In this report we present the genetic aspects and suggest that the blepharophimosis syndromes are likely candidates for a contiguous gene syndrome.

\section{Case reports}

CASE 1

This patient presented at the age of 28 years with secondary amenorrhoea and infertility. Menarche had occurred at the age of 12 years but from 23 years she had primary infertility with confirmed anovulation. Blepharophimosis had been noted from birth and several surgical procedures had been carried out on the eyelids. There is no family history of blepharophimosis (fig 1). She is of normal intelligence and has no dysmorphic features.

CASE 2

This patient presented at the age of 26 years with a history of increasing oligomenorrhoea and then amenorrhoea for four years. She had a normal menarche at the age of 13 years. Blepharophimosis was noted at birth and her eyelids were operated on in childhood. Phenotypically she is a normal female, height $163 \mathrm{~cm}$, weight $70 \mathrm{~kg}$, and head circumference $56 \mathrm{~cm}$. She had ptosis, small palpebral fissures (outer canthal distance $7 \mathrm{~cm}$ ), mongoloid slant of the fissures, microphthalmia, and epicanthus inversus. There are no other dysmorphic features. The palate is normal as are her hands and feet. Tooth eruption occurred normally and her teeth are 


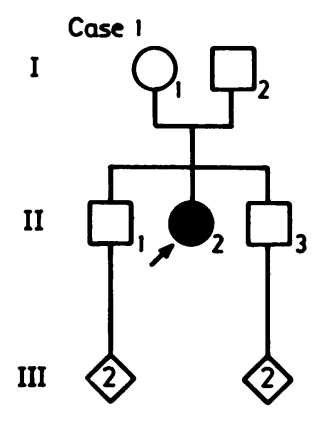

IV

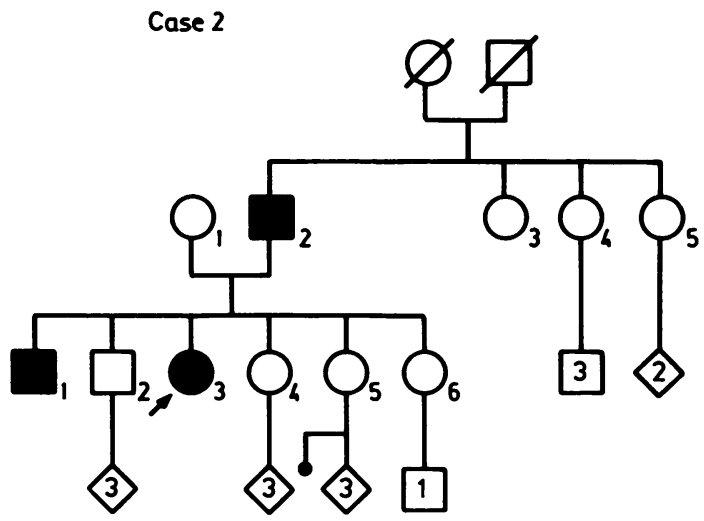

Case 3,4

$$
\text { I Case } 3,4
$$

II

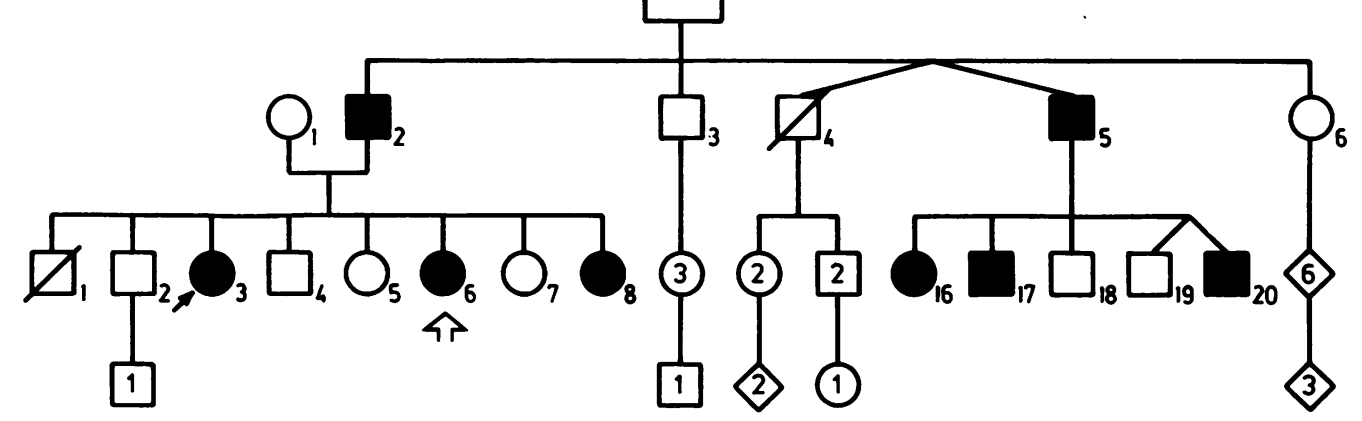

FIG 1 Pedigrees of the four cases. In case 1 there are no other affected subjects suggesting a spontaneous new mutation. In cases 2, 3, and 4 there is dominant inheritance. The proband in the third family is case 3 (closed arrow) and her sister (open arrow) is case 4. The carrier males are not infertile. There is no history in any family of undue spontaneous abortion, stillbirth, or neonatal death among the offspring of affected males. There were no other genetic disorders in these families.

normal. She completed a university science course. Her father and brother are affected (fig 1).

\section{CASE 3}

This patient presented at the age of 28 years with a two year history of secondary amenorrhoea following increasing oligomenorrhoea from the menarche at the age of 13 years. Blepharophimosis had been operated on in childhood. She is of normal intelligence and works as a computer operator. She has minimal dysmorphic features including low set ears, short neck, and a low posterior hair line. She has short, upward slanting palpebral fissures, ptosis, and epicanthus inversus (fig 2). Height is $170 \mathrm{~cm}$, weight $87 \mathrm{~kg}$, and head circumference $57.5 \mathrm{~cm}$. Her family are all tall and solidly built. Her palate is normal. Tooth eruption was not a problem in childhood and at 28 years all teeth are present and normal. Her pedigree is shown in fig 1 in which eight other affected family members are shown. Her female cousin (III.16) had blepharophimosis surgically. treated in childhood, is now aged 26 years, of normal intelligence, and also has secondary amenorrhoea. Her sister (III.8) had blepharophimosis operated on in childhood and is currently under investigation for secondary amenorrhoea at 16 years of age.

\section{CASE 4}

This patient is the sister of case 3 (III.6 in fig 1). She presented at the age of 20 years with a history of a normal menarche at the age of 12 years but had subsequently had only four menstrual periods, the most recent at 18 years of age. Blepharophimosis was apparent at birth and operated on in childhood. She has some dysmorphic features, more pro- 


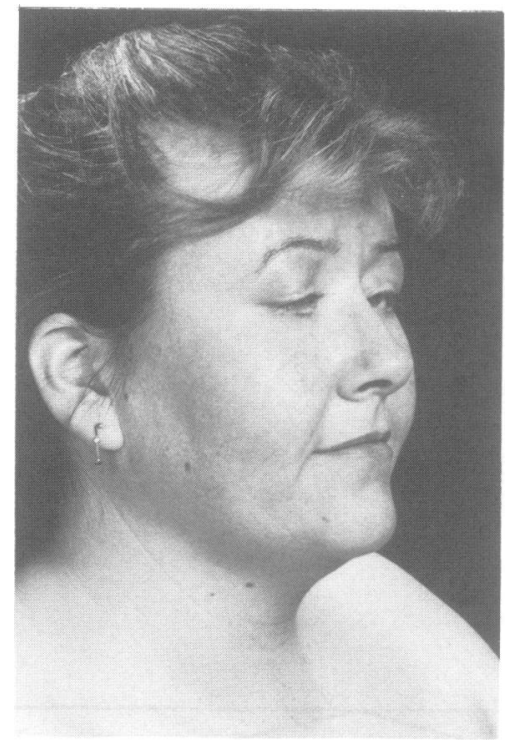

FIG 2 Case 3. Lateral view of face shows the slightly low set, immature ears and short neck. Note the typical eye features found in adult BPES after surgery in childhood.

nounced than in the other cases. These include micrognathia and retrognathia, pointed chin, short neck, and low set, triangular, cup shaped ears. The ocular features are similar to the other cases. Height is $172 \mathrm{~cm}$, weight $63.5 \mathrm{~kg}$, and head circumference $57 \mathrm{~cm}$. The palate is normal. Tooth eruption was physiological and the teeth are now normal. She has bilateral clinodactyly of the fifth fingers. She is of normal intelligence, managing her own business.

\section{CHROMOSOMAL STUDIES}

Cases 2, 3, and 4 underwent detailed blood karyotype analysis with high resolution GTG banding to the 800 to 900 band stage ${ }^{14}$ and also BrdU R banding. These all showed a normal $46, \mathrm{XX}$ female chromosome complement with no detectable abnormality. In each case one $\mathrm{X}$ chromosome was late replicating, showing the normal inactivation pattern. No microdeletion or small structural rearrangement could be detected on any chromosome.

In addition, case 4 had long term culture of ovarian tissue and skin fibroblasts and karyotype analysis of these tissues showed the same karyotype as in peripheral blood. DNA was extracted from peripheral blood of cases 2 and 3. Fibroblast cells from the ovarian tissue and skin of case 4 were stored in liquid nitrogen.

\section{Discussion}

The likelihood of a contiguous gene syndrome being detected cytogenetically is small. There are 50000 genes per haploid set. The 2000 band stage of resolution ${ }^{14}$ gives an average of 25 genes per band. ${ }^{15}$ Even at this stage of resolution gene deletion or DNA rearrangement cutting across two genes would be missed cytogenetically. There have been cases of subjects possessing three or four genetic disorders, all known to localise on $\mathrm{Xp}$, in which molecular studies were required to confirm an enormous deletion in DNA terms but a minute, barely detectable deletion at the cytogenetic level. ${ }^{2}{ }^{16} \mathrm{We}$ achieved a resolution to the 800 to 900 band stage and at this stage there are an average of 50 genes per band. Hence, lack of a detectable difference in high resolution banding pattern in any chromosome does not exclude a CGS. Nevertheless, high resolution studies should always be undertaken in a suspected CGS in the chance of finding a microdeletion or a structural rearrangement as this would considerably aid gene localisation and mapping. To this end, all cases of BPES syndrome should have cytogenetic studies performed, particularly if mental retardation or facial dysmorphic features are present.

Blepharophimosis occurs as an isolated congenital anomaly ${ }^{7}$ which may also have other ophthalmic signs, such as microphthalmia, ptosis, mongoloid slant of the fissures, and epicanthus inversus. These may be part of a broader spectrum of aberrations, not all of which are apparent at birth, including hypodontia ${ }^{8}$ mental retardation, and facial dysmorphic signs (high palate, short neck, cup shaped, low set ears, pixie face with pointed chin, and clinodactyly). Two of our cases had some of the dysmorphic signs (fig 2) which have been described. Thus there is clinical heterogeneity in the developmental features of the face accompanying the BPES. There is also heterogeneity of ovarian function manifesting after puberty and Zlotogora et al ${ }^{12}$ suggested the type 1 and type 2 classification to cover this aspect of BPES.

Control of ovarian function is known to reside with genes on the $\mathrm{X}$ chromosome. Females with Turner's syndrome and only one $X$ chromosome form ovaries and follicles normally but subsequent maintenance of these follicles is deficient and by birth the majority of such patients have afollicular streak ovaries. ${ }^{17}$ Other chromosomal anomalies, such as deletion of $\mathrm{Xq},{ }^{4}$ support this concept of $\mathrm{X}$ chromosome function. However, our cases being 
autosomal in inheritance, clearly indicate that there are autosomal genes whose function is maintenance of ovarian follicles during childhood and after puberty. Localisation of the autosome and site concerned may well come from cytogenetic studies, such as by detection of a translocation. Males with BPES may not require the action of this gene after puberty for maintenance of testicular function. Our cases all had experienced a normal menarche so that their ovarian dysfunction could not be the result of the action of the gene in utero. ${ }^{7}$ Other conditions have been reported where there is a familial link with disturbances of ovarian function. These include polycystic ovarian disease (Stein-Leventhal syndrome) in which some families show autosomal dominant inheritance ${ }^{18}$ but there is no evidence of linkage with dysmorphic features or mental retardation in polycystic ovarian disease. Females with galactosaemia have a similar menstrual history ${ }^{19}$ and there are also differences between ovarian and testicular function in galactosaemia ${ }^{20} 21$ as there are in the BPES.

Using the guidelines of Schmickel, ${ }^{1}$ we suggest that the blepharophimosis ovarian failure syndrome is a candidate for CGS. It is a complex and heterogeneous collection of features. Dominant inheritance has been shown, although this is not essential for a CGS. In case 1 there were no other affected family members but cases 2,3 , and 4 come from families showing autosomal dominant inheritance. There is father to son transmission in both families. Further, it is difficult to see how ovarian failure and blepharophimosis could be pleiotropic effects of one gene as they are not obviously related. However, many single gene defects affect a range of disparate organs and in myotonic dystrophy the testis is affected as well as the face. ${ }^{22}$ Also, the casual association in some cases of dysmorphic features, such as in our cases 3 and 4 , and other features suggests a situation similar to the aniridia, genital anomalies, retardation syndrome (the AGR triad) where it has been shown that isolated aniridia occurs with a single break within $11 \mathrm{p} 13$ while the full syndrome with mental retardation, dysmorphic features, and hypospadias occurs with larger deletions of DNA within the $11 \mathrm{p} 13$ region. ${ }^{23}$ Finally, the severity of symptoms may reflect the number of genes involved. Severe defects include mental retardation because intellectual development requires a complex series of events. Our cases were not retarded. Cases 1 and 2 have no features other than blepharophimosis and ovarian failure while cases 3 and 4 have dysmorphic features as well, so that the defect in them is presumed to be larger. The model of CGS allows for sequential expression of genes; the ocular defect in this syndrome may express itself during the third month of intrauterine life ${ }^{7}$ while the maintenance of ovarian function fails later.

\section{References}

1 Schmickel RD. Contiguous gene syndromes: a component of recognizable syndromes. J Pediatr 1986;109:231-41.

2 Francke U, Harper JF, Darras BT, et al. Congenital adrenal hypoplasia, myopathy and glycerol kinase deficiency: molecular genetic evidence for deletions. Am J Hum Genet 1987;40: 212-27.

${ }^{3}$ Greenberg F, Valdes C, Rosenblatt HM, Kirkland JL, Ledbetter DH. Hypoparathyroidism and T cell immune defect in a patient with 10p deletion syndrome. J Pediatr 1986;109:489-92.

4 Krauss CM, Turksoy RN, Atkins L, McLaughlin C, Brown LG, Page DC. Familial premature ovarian failure due to an interstitial deletion of the long arm of the $\mathrm{X}$ chromosome. $\boldsymbol{N}$ Engl J Med 1987;317:125-6.

5 Kohn R, Romano PE. Blepharoptosis blepharophimosis, epicanthus inversus and telecanthus - a syndrome with no name. Am J Ophthalmol 1971;72:625-32.

${ }^{6}$ Moraine G, Titeca C, Delplace M, Grenier B, Lenoel Y, Ribadeau-Dumas JL. Blepharophimosis familial et sterilite feminine: pleiotropoisme ou genes lies? J Genet Hum 1976;24 (suppl):125-32.

7 Oley C, Baraitser M. Blepharophimosis, ptosis, epicanthus inversus syndrome (BPES syndrome) J Med Genet 1988;25: 47-51.

${ }^{8}$ Ohdo S, Madokoro H, Sonoda T, Hayakawa K. Mental retardation associated with congenital heart disease, blepharophimosis, blepharoptosis, and hypoplastic teeth. J Med Genet 1986;23:242-4.

9 Say B, Barber N. Mental retardation with blepharophimosis. $J$ Med Genet 1987;24:511.

10 Townes PL, Muechler EK. Blepharophimosis, ptosis, epicanthus inversus and primary amenorrhoea. Arch Ophthalmol 1978;97:1664-5.

11 Jones CA, Collin JRO. Blepharophimosis and its association with female infertility. $\mathrm{Br} J$ Ophthalmol 1984;68:533-4.

12 Zlotogora J, Sagi M, Cohen T. The blepharophimosis ptosis and epicanthus inversus syndrome: delineation of two types. $\mathrm{Am} \mathrm{J}$ Hum Genet 1983;35:1020-7.

13 Fraser IS, Shearman RP, Smith A, Russell P. An association between blepharophimosis, resistant ovary syndrome and true premature menopause. Fertil Steril 1988;50:747-51.

14 Yunis JJ. High resolution banding of human chromosomes. Science 1976;191:1268-9.

15 Weatherall DJ. How genes work and how they can be examined. In: The new genetics and clinical practice. Oxford: Oxford University Press, 1985:46.

${ }^{16}$ Harper PS. Isolating the gene for Duchenne muscular dystrophy. Br Med J 1986;293:773-4.

17 Connor JM. Prenatal diagnosis of the Turner syndrome: what to tell the parents. $\mathrm{Br}$ Med $J$ 1986;293:711-12.

18 Cooper HE, Spellacy WN, Prem KA, Cohen WD. Hereditary factors in the Stein-Leventhal syndrome. Am J Obstet Gynecol 1968;100:371-87.

${ }^{19}$ Fraser IS, Russell P, Greco S, Robertson DM. Resistant ovary syndrome and premature ovarian failure in young women with galactosaemia. Clin Reprod Fertil 1986;4:133-6.

${ }^{20}$ Kaufman FR, Kogut MD, Donnell GN, Goebelsmann U, March C, Koch R. Hypergonadotrophic hypogonadism in female patients with galactosemia. $N$ Engl J Med 1981;304: 804-8.

21 Chen YT, Mattison DR, Bercu BB, Schulman JD. Resistance of the male gonad to a high galactose diet. Pediatr Res 1984;18: 345-8.

22 Smith DW. Recognizable patterns of human malformation. Philadelphia: Saunders, 1982:162-3. 
${ }^{23}$ Moore JW, Hyman S, Antonarakis SE, Mules EH, Thomas GH. Familial isolated aniridia associated with a translocation involving chromosomes 11 and 22 [t(11;22)(p13;q12.2)] Hum Genet 1986;72:297-302.
Correspondence to Dr A Smith, Cytogenetics Unit, Oliver'Latham Laboratory, Department of Health NSW, PO Box 53, North Ryde, NSW 2113, Australia. 